\title{
Picosecond Phase-Coniugation Relection and Gain in Saturable Absorbers by Degenerate Four-Wave Mixing
}

\author{
J.O. Tocho, W. Sibbett, and D.J. Bradley \\ Biackett Laboratory. Inoerial College, \\ London. SW7 282 , England
}

Reprint of "picosecond Phenomena Vol. II". Springer-Verlag Heldelberg 1980.

More reliable mode-locking and bandwidth-limited pulses of shorter durations are obtained when the high:-reflectivity mirror is inmersed in the saturable absorber solutions used to passively mode-lock pulsed and CW dye lasers, Meodymium and ruby lasers [1]. This result had been previously explained $[2,3]$ by preferential saturation of the absorber at the antinodes of the standing waves in the neighbourhood of the mirror, particularly when the dye cell length is comparable to the laser pulse length. !lith the recent demonstration of phase conjugation reflection in many materials by degenerate nonlinear mixing [4] involving local saturation of absorption [5] it seemed time!y to investigate picosecond phase-conjugation in DOOCI and other saturaole abscrcers comonly used for mode-locking dye lasers. Our results indicate that. in addition to preferential saturation, phase conjugation effects contribute to the improved perfomance of the immersed mirror mode-locking dye cell, even when the laser beam is focussed on to the mirror as in the case of $C_{\text {r d }}$ dye lasers $\{6\}$. Photoismer effects [7\} are also shown to be important in tre phase-conjugation process, and play a Iominating role as the laser is tunec to longer wavelengths.

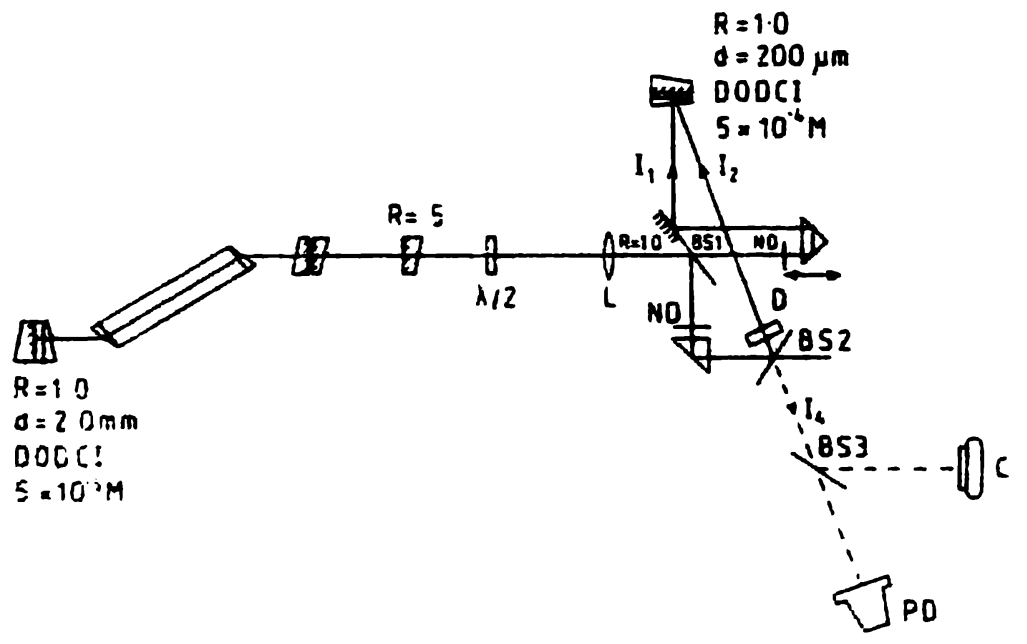

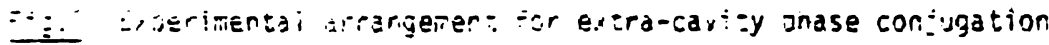


A 1.2us train of $50 \mathrm{\mu J}, 5 p s$ pulses from a flashlamp pumped mode-lucked dye laser [I] was divided by a beansplitter to generate pumping pulses of highintensity $I_{1}$ and low-intensity $I_{2}$ probe pulses, arranged to arrive simultaneously the extra-cavity retroflecting cell by appropriate adjustment of the prism optical delay lines. The pulses were focussed into the $200 \mathrm{um}$ path length dye cell to give peak intensity of $2500 \mathrm{mu} \mathrm{cm}^{-2}$ in an area of ilm diameter. DODCI, DQTCI and Oxazine I dissolved in a range of solvents (ethanol, methanol, and glycerol) were employed. The results were independent of the solvent used and phase conjugation reflectivity was produced by all three dyes. Most of the work was carried out with DODCI.

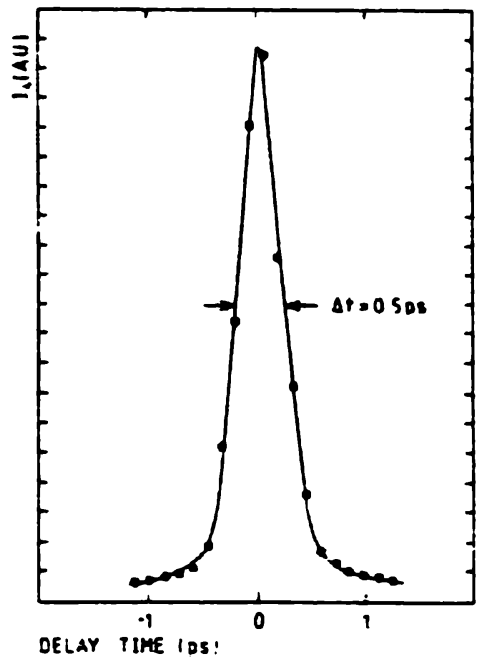

Fig.2(a) Reflected intensity dependence on delay between pump and probe pulses

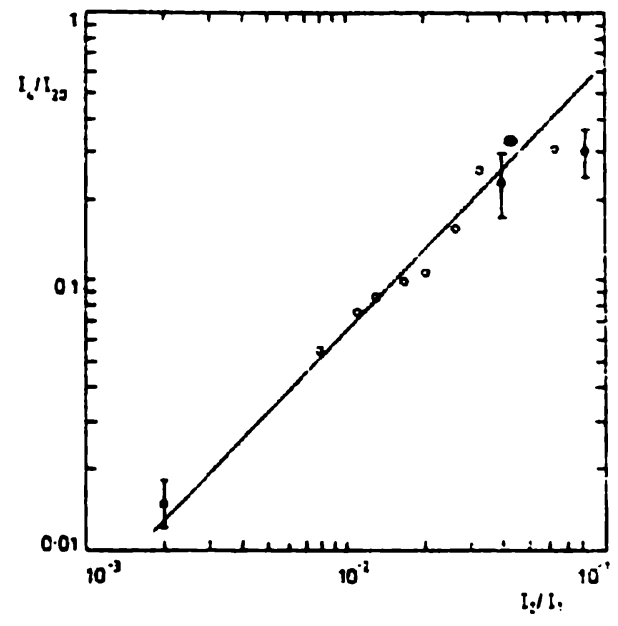

Fig.2(b) Reflected intensity $I_{2}$ cependence on probe intensity I? $\left(I_{20}=36 \mathrm{Mh} \mathrm{cm}^{-2} ; I_{1}=4.40 \mathrm{mi} \mathrm{cm}^{-2}\right.$ )

Figure 2 (a) shows the variation of reflected intensity for DODCI as a function of the delay between the object and pump pulses. The half-width of $0.5 p s$, averaged over a complete pulse train, compares with a coherence time of 0.22 ps for the $2.3 \mathrm{~mm}$ total bandwidth. Self-phase modulation spectral broadening along the dye lasers pulse train [7] accounts for the difference. As expected there was a quadratic dependence of reflectivity upon pump intensity $[8,9 j$. The output intensity increased linearly with the object wave intensity up to $217 \mathrm{MH} \mathrm{cm}^{-2}$ when saturation set in at a power reflectivity of $4.50 \%$ (Fig.2(b)). The dependence of reflectivity upon DCDCI concentration (Fig.3) is a gooc fit to the theoretical relation (exp - 2ad) $(1-\exp (-22 d))^{2}$ [9] with an optimum concentration of $5.5 \times 10-4 \mathrm{M}$, the typical concentration giving oprimum mode-locking performance. Confimation of wavefront phase conjugation was obtained by correcting for the effect of a cylindrical lens distorter. Phase-conjugate reflection was also obtained viten the laser was not node-locked. 


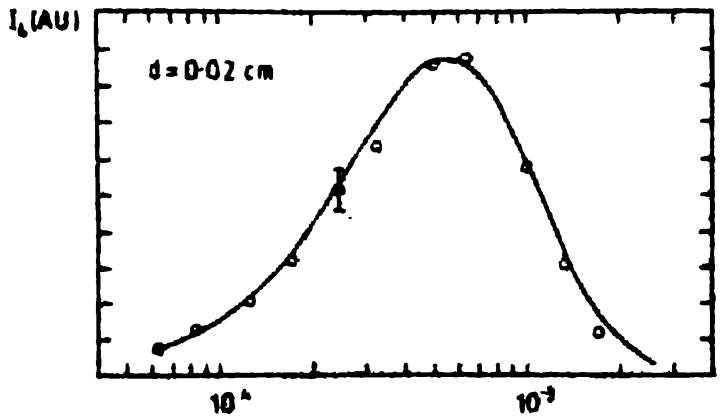

MOLAR CONCENTRATIOA of DOOCI

Fig. 3 Reflected intensity dependence on DOOCI concentration. Swooth curve $\left.I_{0} \exp -2 a d\right)\left(1-\exp 1-E_{2} d\right)=, 2=$ absorption coefficient, $d=0.2$ atian

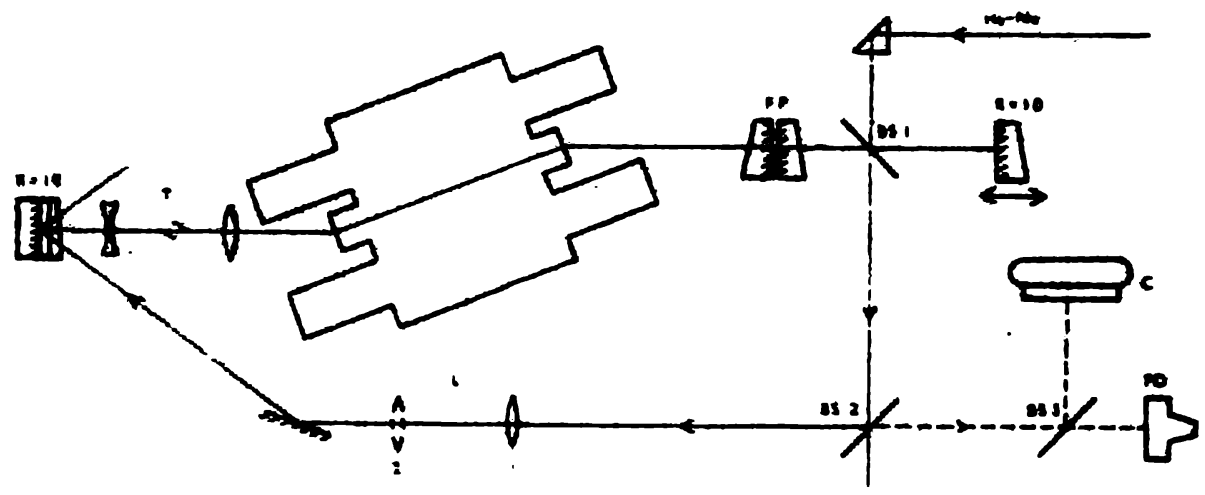

Fig.: intra-cavity pnase conjjgation experimental arrangement.

The experimental arrangemere for intracavity phase conjugation is shown in :ig.4. At a DSOC: concentration of $2.5 \times 10^{-}-\mathrm{H}$ in a cell of 0.2 mickness a reflectivity of 1 . was obtained. Fig. 5 shows the return beam profile when (d) the cell mirror was at tre foeus of lens L: (b) the lens was displaced by $5 \mathrm{~cm}$; the fluorescence patterms ( $c$ and d) for these two posittons respectively and (e) ine probe bean reflected ty a mirror. Inside the mode-locked laser cavity, prase-conjugation reflection syould be produced with greater fidelity $\{10$ ! because the pump beans and the effective probe beams experience the same distortion in passing through the laser. medium. In the arrangement of Fig. 4 tnis was not necessarily the case since the pump beams will have made an extra transt? :nrougri she laser dye solution. Also, the temporal structure of the pung team will have been changed III ty tnis extra transit trrough the ampitifjirg redium. As with tre extra-cavity arrangemert coincidence of the sump er.c orose oulses to within tre coherence time was needed to achieve phase conjugation reflectivity. Thus intra-cavtty phase-sonjugation will sotr cerroet for Fremal disizr:ion ane tend to produce sandwiath-limited fulses, since ancwid:ri-limited strucsures from the initial intensity fluc the sazuratis assorser. 

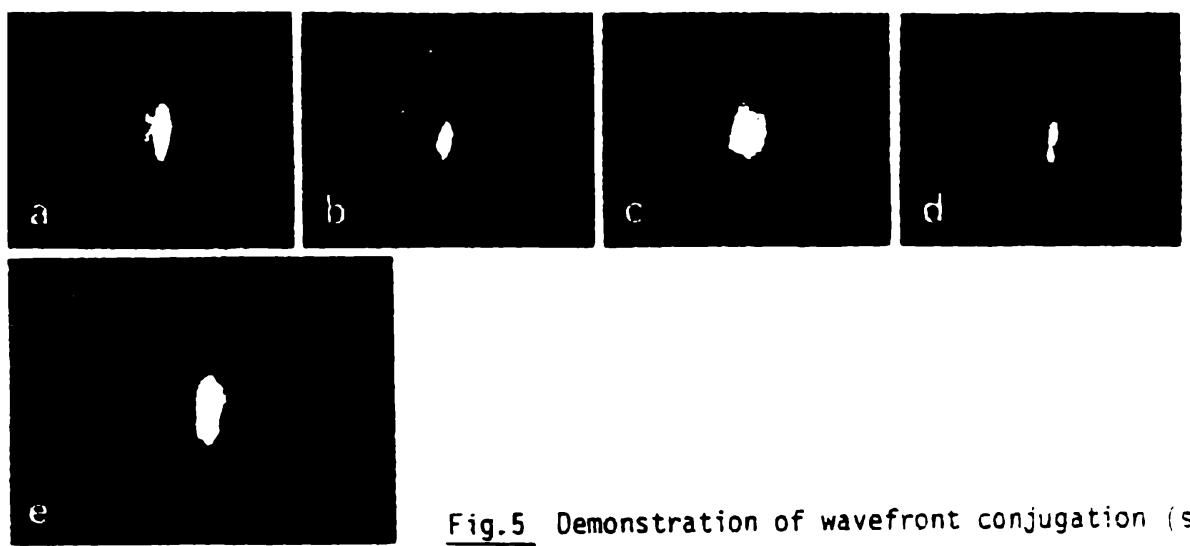

Fig. 5 Demonstration of wavefront conjugation (see text
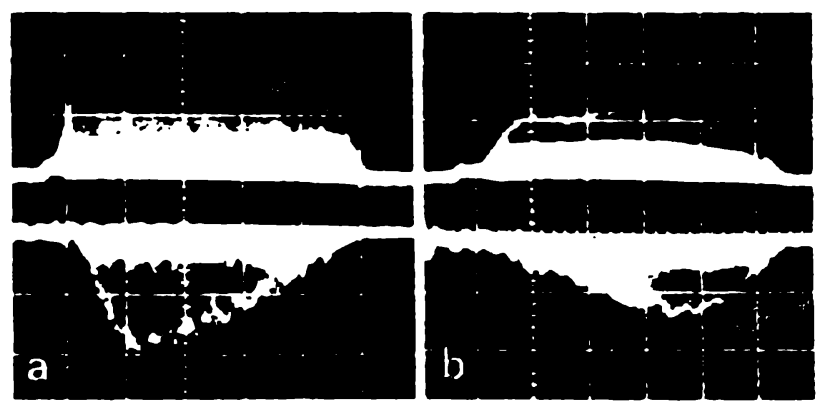

Fig.6(a) Upper Pump mode-locked pulse train (605 nm) Lower Reflected pulse train.

Fig.6(b) As for Fig.6(a) but laser tinned to operate at $517 \mathrm{~nm}$. "ote restructuring of mode-locked plise train erivelope di: to generation of OCCC: Dnctoisomer ar. subsequent phase-conjugation reflection.

The effect of photoisomer generation in DOOCI [7] was clearly seen by a reflected pulse delay of $.500 \mathrm{~ns}$, compared with tr.e pump pulse, for a OCDC: $\left(5 \times 10^{-}-M\right)$ cell pumped by a $617 \mathrm{~nm}$ unmode-locked laser puise. At. $586 \mathrm{~nm}:$ re eficiciency reached 150: with zero delay. That the delay at longer wavelergirs arises from photoisomer generation is confirmed by $\bar{r} i g .6$. Fig. $E(a)$ shows the fump and reflected pulses for a $605 \mathrm{~nm}$ mode-locked pulse irain, while fig.6(b) shows a drastic restructuring and delay 'time scale 200 ns major division: when the laser was tuned to $617 \mathrm{~m}$. At this longer wave?ength phase conjugation would be more efficient for the DCCC 1 photcisomer created at the ceginning of the srain, than for the nomal form [1!. The oe!dy in the ouild-so of the photoisomer coricentration could be manifulated for the production of .azeiengir-tenendent multinlexing for apn'ications in reai-time rolograpily, data and jicture processing and waveierigtr filtering, 31 with picosecone iesponse timies. 
Thus with a tunable dye laser it is Dossible to produce phase conjugation h'itn gain and with picosecond ime response. By exploiting photoisomer Effec wavelengtirdependent variable delays and pulse envelope restructuring is ottained. Since phase conjugation requires coincidence within the conerence tine, bandwidth-limited pulses will be preferentially produced cy a retroreflecting atsorter dye cell. Amplification and phase conjugation in BDN saturable absorber by 13 ns pulses of a ND:YAG O-switched laser and simultancous intra-cavity Q-switching and phase-conjugation reflection has also recently been reported [il].

\section{References}

1. D.J. Bradley: Topics in Applied Physics 18, "Lll tra-short light pulses" ed: S.L. Shapiro (Springer-Verlag, Heidelberg) $17-81$ and refs. therein

2. D.J. Bradley, G.H.C. New and S.J. Caughey: Opt.Commun. 2, 41 (1970)

3. G.H.C. New: IEEE J.Quant. Electron. GE-10,115 (1974)

4. B.I.Stepanov, E.V.Ivakhin and F..S.Rubanov: Sov.Phys.Dok1.16, 45 (1971)

5. A.D. Kudriaytzeva et.al.: Opt. Comnun. 26, 446 (1978)

6. 1.S. Ruddock and L.J. Bradley: Appl.Phys.Lett. 29, 296 (1976)

7. E.E. A.rthurs, D.J. Bradley and A.G. Roddie: Appl.Phys.Lett. 19, 480 (197!) 20,125 (1972)

8. P.F. Liao and D.M. Eloom: Opt.Lett. 3,4 (1979)

9. R.L. Abrams and R.C. Lind: Opt.Lett.2, 94 (1978)

10. W.M. Grossman and D.Y. Shemwell: J.Appl.Phys.51, 914 (1980)

i1. E. .. Moses and F.Y.Hu: Opt.Lett. 5, 64 (1980) 